\title{
Atributos físicos, químicos e biológicos de um Latossolo de cerrado em plantio de espécies florestais
}

\author{
Luciana Gomes da Silva(1), lêda de Carvalho Mendes(2), Fábio Bueno Reis Junior ${ }^{(2)}$, \\ Marcelo Ferreira Fernandes(3), José Teodoro de Melo(2) e Eiyti Kato $^{(1)}$
}

(1)Universidade de Brasília, Faculdade de Agronomia e Veterinária, Caixa Postal 04508, CEP 70910-970 Brasília, DF. E-mail: luciana.silva@conab.gov.br, kato@unb.br (2)Embrapa Cerrados, Caixa Postal 08223, CEP 73310-970 Planaltina, DF. E-mail: mendesi@cpac.embrapa.br, fabio@cpac.embrapa.br, teodoro@cpac.embrapa.br ${ }^{3}$ Embrapa Tabuleiros Costeiros, Avenida Beira Mar, № 3.250, CEP 49025-040 Aracaju, SE. E-mail: marcelo@cpatc.embrapa.br

\begin{abstract}
Resumo - O objetivo deste trabalho foi avaliar o impacto de plantios florestais nos atributos físicos, químicos e biológicos de um Latossolo Vermelho-Amarelo de cerrado. Amostras de solo foram coletadas à profundidade de 0 a $10 \mathrm{~cm}$, em áreas cultivadas há mais de 20 anos com pínus (Pinus tecunumanii), eucalipto (Eucalyptus grandis) ou carvoeiro (Sclerolobium paniculatum). Uma área adjacente de cerrado nativo foi incluída como referência do solo original. Foram observados, em relação ao cerrado, aumentos na densidade do solo sob pínus e eucalipto, redução na macroporosidade sob pínus, menores teores de matéria orgânica sob pínus e eucalipto, além de decréscimos no $\mathrm{pH}$ e na saturação por bases e incremento da saturação por alumínio nos cultivos com pínus e carvoeiro. O carbono da biomassa microbiana sob pínus, eucalipto e carvoeiro foi aproximadamente a metade do carbono sob cerrado. Atividades de fosfatase ácida e arilsulfatase foram inibidas pelo pínus e estimuladas pelo carvoeiro. Entre os reflorestamentos avaliados, o pínus promoveu a redução mais acentuada da qualidade do solo de cerrado. As variáveis microbiológicas foram as mais sensíveis em detectar o efeito dos diferentes reflorestamentos na qualidade do solo.
\end{abstract}

Termos para indexação: Eucalyptus grandis, Pinus tecunumanii, Sclerolobium paniculatum, carbono da biomassa microbiana, enzimas do solo, qualidade do solo.

\section{Physical, chemical and biological attributes of a cerrado Oxisol under different forest species}

\begin{abstract}
The objective of this study was to evaluate the impact of forest plantations on the physical, chemical and microbiological attributes of a cerrado Oxisol. Soil samples were collected at $0-10 \mathrm{~cm}$ depth from sites cultivated with pinus (Pinus tecunumanii), eucalyptus (Eucalyptus grandis) and carvoeiro (Sclerolobium paniculatum) for over 20 years. An adjacent native cerrado area was used as a reference of the original soil conditions. It was observed in relation to the native cerrado: increases in soil density under pinus and eucalyptus, reduction in the macroporosity under pinus, lower organic matter contents under pinus and eucalyptus, besides decreases in the soil $\mathrm{pH}$ and in the base saturation under pinus and carvoeiro along with an increase in aluminum saturation. Soil microbial biomass carbon under the pinus, eucalyptus and carvoeiro sites was about half of that found under cerrado. The activities of acid phosphatase and arylsulfatase were inhibited by pinus and stimulated by carvoeiro. Among the forest systems evaluated, pinus promoted the greatest reduction on soil quality. The microbiological variables were the most sensitive to detect the effects of these systems on soil quality.
\end{abstract}

Index terms: Eucalyptus grandis, Pinus tecunumanii, Sclerolobium paniculatum, microbial biomass carbon, soil enzymes, soil quality.

\section{Introdução}

O Brasil situa-se entre os dez países com maiores áreas de florestas plantadas do mundo. Essa área está estimada em 5,74 milhões de hectares, dos quais cerca de $90 \%$ são constituídos por eucalipto e pínus (Sociedade Brasileira de Silvicultura, 2007). Esses reflorestamentos apresentam rápido crescimento e excelente produtividade (Juvenal \& Mattos, 2002).
Em razão das condições edafoclimáticas e fisiográficas, favoráveis ao estabelecimento de plantios de eucalipto e pínus nas décadas de 1970 e 1980, os reflorestamentos com essas espécies tiveram grande expansão na Região do Cerrado (Juvenal \& Mattos, 2002).

A perspectiva de aumento da demanda mundial por celulose e por madeira certificada, a possibilidade da expansão de sistemas integrados lavoura-pecuária- 
floresta, e o uso estratégico de florestas para sequestro de carbono, no âmbito dos mecanismos de desenvolvimento limpo, fazem crescer a demanda por tecnologias voltadas à produção florestal sustentável e por estudos sobre os impactos dessa atividade no meio ambiente.

Por estarem mais diretamente associados à produtividade das plantas, até recentemente, apenas os atributos químicos e físicos do solo eram considerados na avaliação dos impactos e da capacidade produtiva dos plantios florestais (Schoenholtz et al., 2000). Contudo, a crescente valorização dos serviços ambientais, proporcionados pelos sistemas florestais, tem estimulado a inclusão de atributos biológicos do solo entre os parâmetros que avaliam as práticas de manejo florestal e seus impactos ao meio ambiente (Baretta et al., 2005; Chaer \& Tótola, 2007).

O conhecimento do funcionamento biológico e da ecologia microbiana dos solos brasileiros, em áreas de floresta, ainda tem muitas lacunas. Este trabalho teve como objetivo avaliar o impacto de plantios florestais nos atributos físicos, químicos e biológicos de um Latossolo Vermelho-Amarelo de cerrado.

\section{Material e Métodos}

O estudo foi conduzido em um Latossolo VermelhoAmarelo, textura argilosa, na área experimental da Embrapa Cerrados, Planaltina, DF $\left(15^{\circ} 35^{\prime} 30^{\prime \prime} \mathrm{S}\right.$ e $47^{\circ} 42^{\prime} 0$ "W, altitude de $1.175 \mathrm{~m}$ ). O clima é do tipo tropical estacional (Aw), conforme classificação de Köppen, com precipitação anual média de $1.500 \mathrm{~mm}$.

Os sistemas avaliados foram os reflorestamentos de pínus (Pinus tecunumanii), com 21 anos (espaçamento $3 \times 3 \mathrm{~m})$, de eucalipto (Eucalyptus grandis), com 24 anos (espaçamento $3 \times 2 \mathrm{~m}$ ) e de carvoeiro (Sclerolobium paniculatum Vogel), leguminosa nativa do Cerrado, com 21 anos (espaçamento $3 \times 2 \mathrm{~m}$ ). Para o estabelecimento desses plantios, a vegetação original de cerrado foi removida, e o solo foi gradeado e sulcado. A adubação com N-P-K e a calagem foram feitas em covas. Desde a implantação das espécies florestais, não houve corte das árvores. Por ocasião da amostragem do solo, as plantas de pínus, eucalipto e carvoeiro apresentavam diâmetro médio à altura do peito de 93,102 e $54 \mathrm{~cm}$, respectivamente. Para fins de amostragem, os reflorestamentos foram subdivididos em três parcelas de 30x40 m na plantação de pínus, de
$15 \times 15 \mathrm{~m}$ na de eucalipto e de 6x50 m na de carvoeiro. Os dados apresentados constituem as médias dessas três parcelas. Como referência das condições originais do solo, foi utilizada uma área adjacente sob vegetação nativa do tipo cerrado sensu stricto, que também foi subdividida em três parcelas de 30x40 m.

A coleta do solo foi realizada em março de 2006 (período chuvoso). As camadas de serapilheira e húmus apresentavam espessuras médias de 7,8, 2,7 e $6,3 \mathrm{~cm}$, nos plantios de pínus, eucalipto e carvoeiro, respectivamente, e foram removidas antes da coleta do solo, realizada na camada de $0-10 \mathrm{~cm}$. As determinações de densidade e porosidade do solo (Embrapa, 1997) foram realizadas em amostras indeformadas (duas subamostras por parcela). A porosidade total foi estimada a partir do volume de água do solo saturado $(0 \mathrm{kPa})$. A macroporosidade e a microporosidade foram determinadas pelo método da mesa de tensão, com o volume de macroporos correspondente à massa de água retida entre 0 e $-6 \mathrm{kPa}$, e o de microporos à água retida a tensões inferiores a $-6 \mathrm{kPa}$.

Amostras deformadas foram retiradas para as análises dos atributos químicos e biológicos (dez subamostras por parcela, para compor uma amostra). As amostras foram homogeneizadas e passadas em peneira de malha de $4 \mathrm{~mm}$. Resíduos de plantas e raízes foram removidos. As amostras de solo foram armazenadas entre 3 e $7^{\circ} \mathrm{C}$, até o momento da realização das análises.

Após secagem das amostras de solo ao ar, foram determinados o $\mathrm{pH}$ em água e os teores de matéria orgânica, $\mathrm{P}, \mathrm{Ca}, \mathrm{Mg}, \mathrm{K}$, e Al. Os teores de matéria orgânica foram determinados pelo método de Walkley \& Black (Nelson \& Sommers, 1982), e os de Ca, Mg e $\mathrm{Al}$ foram extraídos com $\mathrm{KCl} 1 \mathrm{~N}$ e determinados por absorção atômica (Ca e $\mathrm{Mg}$ ) e titulação com $\mathrm{NaOH}$ $0,025 \mathrm{~mol} \mathrm{~L}^{-1}(\mathrm{Al})$; $\mathrm{Pe} \mathrm{K}$ foram extraídos com o extrator Mehlich-1 e determinados por espectrofotometria de ionização de chama $(\mathrm{K})$ e pelo método do azul de $\mathrm{Mo}$ (P), conforme Embrapa (1997).

O método clorofórmio fumigação-extração (CFE) foi utilizado para as análises de carbono da biomassa microbiana (CBM). Para isso, a umidade do solo $(20 \mathrm{~g})$ foi elevada para $95 \%$ da capacidade de campo (equivalente ao teor de água retido no solo a $6 \mathrm{kPa}$ ), e as amostras foram pré-incubadas no escuro, por sete dias à temperatura ambiente. Em seguida, metade das amostras foi fumigada por 48 horas com clorofórmio livre de álcool. Durante esse período, as amostras não 
fumigadas foram mantidas à temperatura ambiente. O CBM foi determinado conforme Vance et al. (1987), tendo-se usado o fator de correção $(\mathrm{Kec})$ igual a 0,35 . O carbono orgânico do solo (Corg) foi calculado pela divisão do teor de matéria orgânica por 1,724 (Nelson \& Sommers, 1982).

As atividades das enzimas do solo, associadas aos ciclos do carbono (beta-glicosidase), do fósforo (fosfatase ácida) e do enxofre (arilsulfatase), foram determinadas de acordo com Tabatabai (1994).

Por se tratar de um estudo observacional, sem delineamento experimental, a comparação dos dados foi feita com o teste não paramétrico de Wilcoxon $(\mathrm{p}<10 \%)$.

Para visualizar as semelhanças entre as áreas, com base na análise conjunta das variáveis, os sistemas florestais foram ordenados pela técnica de análise de componentes principais (ACP), com uma matriz de variância-covariância. Nessa análise, foram incluídas as variáveis densidade de solo, macroporosidade, microporosidade, porosidade total, matéria orgânica, CTC, pH, saturação por alumínio, CBM, fosfatase ácida, beta-glicosidase e arilsulfatase. Em razão da inclusão de variáveis que refletem diversos processos do funcionamento dos solos, diferenças na ordenação das amostras foram interpretadas como efeito das mudanças, causadas pelas coberturas vegetais, na qualidade geral do solo. Previamente à análise de componentes principais, os dados de cada variável foram relativizados pelos respectivos valores máximos encontrados nas amostras. Essa transformação teve por objetivo excluir o efeito de diferenças na magnitude das unidades das variáveis sobre a ordenação. $\mathrm{O}$ número de componentes principais (CPs) significativos foi selecionado, tendo-se comparado os autovalores reais aos autovalores "broken-stick" de cada CP (Jackson, 1993). Esse procedimento assegura que apenas CPs com mais informação do que a esperada ao acaso sejam interpretados. As variáveis associadas aos CPs foram identificadas pela correlação de Pearson entre os escores das amostras na ordenação e os valores dessas variáveis. A análise multivariada empregada possibilitou a determinação dos escores das variáveis edáficas no espaço das amostras de solo (Figura 1), por meio da técnica da média recíproca (Whittake, 1967), que permite comparar a sensibilidade das variáveis edáficas, para separar as coberturas vegetais. Para essa determinação, os escores das amostras nos eixos da
ACP foram utilizados como pesos (McCune \& Grace, 2002). Os escores das variáveis expressam a tendência central e a amplitude dos valores dessas variáveis, entre as amostras estudadas, e podem ser utilizados para contrastar a sensibilidade das variáveis quanto à resposta a um gradiente ambiental quantitativo (Ter Braak \& Looman, 1986). De acordo com essa estratégia, quanto mais distantes forem os escores das variáveis da origem da ordenação (coordenadas 0 ), mais distintos são os valores medidos para essa variável, entre as amostras localizadas nas extremidades dos gradientes representados em cada eixo

\section{Resultados e Discussão}

Verificaram-se, em relação à vegetação nativa, aumentos na densidade do solo nos plantios de eucalipto e pínus e, também, redução da macroporosidade e aumento na microporosidade no plantio de pínus (Tabela 1). Resultados similares foram observados por Behera \& Sahani (2003), em uma plantação de eucalipto na Índia. Aumentos de densidade do solo em superfície, em sistemas florestais, podem estar relacionados ao tempo de utilização da área, arquitetura do sistema radicular, pouca cobertura do solo durante o período inicial de crescimento das plantas, trânsito de máquinas e implementos agrícolas, e condições de umidade do solo no preparo e plantio das mudas (Costa et al., 2003).

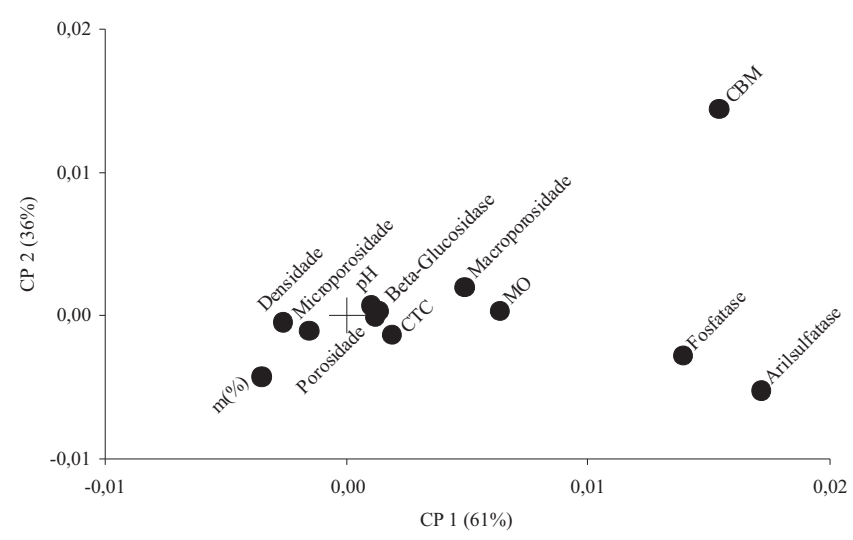

Figura 1. Ordenação das variáveis edáficas no espaço das amostras de solo, determinada pelo procedimento da média recíproca. A distância euclidiana das variáveis até a origem (coordenada 0; indicada pela cruz no centro do gráfico) é proporcional à sensibilidade dessas variáveis em separar as amostras de solo de acordo com a análise de componentes principais da Figura 2. 
Nos plantios de pínus e eucalipto, ocorreram reduções significativas nos teores de matéria orgânica, em relação à área de cerrado (Tabela 2). Resultados semelhantes foram relatados por Fonseca et al. (1993), Zinn et al. (2002) e Behera \& Sahani (2003) e estão associados à oxidação biológica da matéria orgânica original do solo, decorrente de seu preparo e cultivo, do declínio inicial da produção de serapilheira e das mudanças na composição qualitativa da serapilheira que ocorrem nos plantios florestais.

Diferentemente do observado na área sob pínus e eucalipto, o teor de matéria orgânica no plantio de carvoeiro não diferiu da área de cerrado (Tabela 2). Esse resultado pode estar relacionado à quantidade e à qualidade dos resíduos vegetais (serapilheira), retornados ao solo por essa leguminosa. Garay et al. (2003) compararam os teores de matéria orgânica em plantios de eucalipto e da leguminosa Acacia mangium e verificaram que o maior estoque de serapilheira no plantio de acácia (10 $\mathrm{Mg} \mathrm{ha}^{-1}$, em comparação a $5 \mathrm{Mg} \mathrm{ha}^{-1}$ no plantio de eucalipto), aliado à sua menor relação $\mathrm{C} / \mathrm{N}$, resultou em maior teor de matéria orgânica no solo. Binkley \& Giardina (1997) também relataram aumentos nos teores de matéria orgânica e $\mathrm{N}$ total, em plantios de leguminosas florestais.

Em relação às áreas sob cerrado, nas áreas sob pínus e carvoeiro houve reduções no $\mathrm{pH}$ e nos teores de K, Ca e $\mathrm{Mg}$ e aumento médio de $40 \%$ na saturação por Al (m\%) (Tabela 2). Embora a saturação por bases (V\%) do solo sob pínus e carvoeiro não tenha diferido significativamente da saturação por bases do cerrado,

Tabela 1. Propriedades físicas dos solos à profundidade de $0-10 \mathrm{~cm}^{(1)}$.

\begin{tabular}{|c|c|c|c|c|}
\hline Espécie & $\begin{array}{l}\text { Densidade do solo } \\
\left(\mathrm{g} \mathrm{cm}^{-3}\right)\end{array}$ & Microporos & Macroporos & Porosidade \\
\hline Eucalipto & $0,91 \mathrm{a}$ & $32,2 b$ & $31,8 \mathrm{a}$ & $64,7 b$ \\
\hline Carvoeiro & $0,77 b$ & $41,0 \mathrm{a}$ & $30,0 \mathrm{ab}$ & $71,0 \mathrm{a}$ \\
\hline Pínus & $0,87 \mathrm{a}$ & $40,8 \mathrm{a}$ & $26,2 b$ & $67,0 \mathrm{ab}$ \\
\hline Cerrado & $0,78 \mathrm{~b}$ & $35,8 \mathrm{ab}$ & $34,8 \mathrm{a}$ & $70,7 \mathrm{a}$ \\
\hline
\end{tabular}

o valor médio dessa variável foi de cerca de metade da observada sob a vegetação nativa. Decréscimos no $\mathrm{pH} \mathrm{e}$ nos teores de bases e incrementos, nas concentrações de Al extraível em plantações de pínus, comparativamente a pastagens, foram relatados em diferentes solos da Nova Zelândia (Giddens et al., 1997) e da Austrália (Saggar et al., 2001). A liberação de ácidos orgânicos, por acículas em decomposição, e a maior absorção de cátions do que de ânions são possíveis causas da acidificação dos solos sob pínus (Giddens et al., 1997). Ademais, em plantios desta espécie florestal, o acúmulo de acículas na superfície do solo promove a retenção de quantidades consideráveis de nutrientes na serapilheira, o que altera o equilíbrio do sistema solo-planta (Chaves \& Corrêa, 2005). Assim como sob carvoeiro, no presente trabalho, decréscimos no $\mathrm{pH}$ do solo e nos teores de bases também foram relatados em áreas cultivadas com outras leguminosas arbóreas, como Albizia (Rhoades \& Binkley, 1996) e Acacia mangium (Yamashita et al., 2008), em comparação a áreas dominadas por espécies não leguminosas.

Em relação à vegetação do cerrado, o plantio de eucalipto promoveu um acréscimo no teor de $\mathrm{K}$ (Tabela 2), conforme também verificado por Fonseca et al. (1993) e Gama-Rodrigues et al. (2008b). Os teores de $\mathrm{Ca}$ e $\mathrm{Mg}$ e a saturação por bases, no solo com eucalipto, não diferiram em relação ao cerrado nativo, porém foram superiores aos dos plantios de carvoeiro e pínus (Tabela 2). Uma vez que as três espécies foram adubadas somente na sua implantação e não houve replantio, esses resultados podem ser atribuídos à absorção de nutrientes pelo eucalipto, nas camadas mais profundas do solo, e seu retorno via decomposição da serapilheira. Na Austrália, Noble \& Randall (2005) verificaram que o retorno de nutrientes de Eucalyptus cloeziana, na forma de serapilheira, aumentou os teores de $\mathrm{Ca}, \mathrm{Mg}, \mathrm{K}$ e $\mathrm{Na}$ no solo. Zaia \& Gama-Rodrigues (2004) verificaram, em estudos conduzidos no norte fluminense, que o $E$. grandis, em razão dos seus menores teores de lignina, apresentou

Tabela 2. Propriedades químicas dos solos à profundidade de $0-10 \mathrm{~cm}^{(1)}$.

\begin{tabular}{|c|c|c|c|c|c|c|c|c|c|}
\hline Espécie & $\begin{array}{l}\text { Matéria orgânica } \\
\left(\mathrm{g} \mathrm{kg}^{-1}\right)\end{array}$ & $\mathrm{pH}_{\mathrm{H}_{2} \mathrm{O}}$ & $\begin{array}{c}\mathrm{m} \\
(\%)\end{array}$ & $\begin{array}{c}P \\
--- \\
\end{array}$ & $\begin{array}{c}\mathrm{K} \\
-3 \\
----\end{array}$ & $\mathrm{Ca}$ & $\begin{array}{c}\mathrm{Mg} \\
\left(\mathrm{ol}_{\mathrm{c}} \mathrm{dm}^{-3}\right)\end{array}$ & CTC & $\begin{array}{l}\mathrm{V} \\
(\%)\end{array}$ \\
\hline Eucalipto & $29 b$ & $4,86 \mathrm{a}$ & $60 \mathrm{~b}$ & 0,7 & $157 \mathrm{a}$ & $0,47 \mathrm{a}$ & $0,55 \mathrm{a}$ & $11,2 \mathrm{a}$ & $13 a$ \\
\hline Carvoeiro & $42 a$ & $4,57 b$ & $72 a$ & 0,4 & $34 c$ & $0,16 b$ & $0,21 \mathrm{~b}$ & $9,7 \mathrm{ab}$ & $4 b$ \\
\hline Pínus & $30 \mathrm{~b}$ & $4,48 b$ & $70 a$ & 0,7 & $14 d$ & $0,16 \mathrm{~b}$ & $0,18 \mathrm{~b}$ & $8,6 \mathrm{~b}$ & $4 b$ \\
\hline Cerrado & $39 a$ & $4,91 \mathrm{a}$ & $49 b$ & 0,5 & $49 \mathrm{~b}$ & $0,34 \mathrm{a}$ & $0,32 \mathrm{ab}$ & $9,6 \mathrm{ab}$ & $8 \mathrm{ab}$ \\
\hline
\end{tabular}

${ }^{(1)}$ Valores seguidos por letras iguais, nas colunas, não diferem entre si pelo teste de Wilcoxon $(\mathrm{p}<0,10) ; \mathrm{m}$, saturação por alumínio $=100\left[\mathrm{Al}^{3+} /\left(\mathrm{Ca}^{2+}+\mathrm{Mg}^{2+}\right.\right.$ $\left.\left.+\mathrm{K}^{+}+\mathrm{Al}^{3+}\right)\right] ; \mathrm{CTC}=\mathrm{Ca}^{2+}+\mathrm{Mg}^{2+}+\mathrm{K}^{+}+\mathrm{H}^{+}+\mathrm{Al}^{3+} ; \mathrm{V}(\%)$, saturação por bases $=100\left[\left(\mathrm{Ca}^{2+}+\mathrm{Mg}^{2+}+\mathrm{K}^{+}\right) / \mathrm{CTC}\right]$. 
taxas mais elevadas de decomposição de serapilheira e possibilitou maior taxa de ciclagem de nutrientes. Cabe ressaltar que existe, na literatura, grande variação de resultados quanto aos efeitos do eucalipto sobre os atributos químicos do solo (Chaer \& Tótola, 2007; Gama-Rodrigues et al., 2008a). Diferenças de clima, solo, espécies plantadas, ecossistema nativo usado como referência e manejo das áreas reflorestadas tornam imprópria a generalização desses efeitos.

Os teores de $\mathrm{P}$ não variaram significativamente entre as quatro áreas avaliadas, resultado também verificado por Fonseca et al. (1993), em solos sob eucalipto.

Nos três plantios de espécies florestais, ocorreram reduções no $\mathrm{CBM}$ e na relação $\mathrm{CBM} / \mathrm{Corg}$, em relação ao solo sob cerrado (Tabela 3), conforme também observado por Behera \& Sahani (2003), Chaer \& Tótola (2007) e Gama-Rodrigues et al. (2008a). Mesmo após mais de 20 anos do estabelecimento desses sistemas, os níveis de biomassa microbiana não atingiram o patamar observado na área sob cerrado. Além dos efeitos associados à remoção da vegetação nativa e preparo do solo, por ocasião do estabelecimento desses plantios, as reduções no CBM também refletem as alterações relacionadas à quantidade e à qualidade dos resíduos vegetais disponíveis à microbiota sob os sistemas florestais (Gama-Rodrigues et al., 2008a).

Embora os teores de matéria orgânica, no cerrado nativo e no plantio de carvoeiro, tenham sido semelhantes, este último apresentou teor de CBM inferior ao do cerrado. Como o CBM é considerado um indicador sensível de mudanças no solo, esse resultado confirma observações anteriores de que nem sempre esses dois parâmetros estão correlacionados (Marchiori-Júnior \& Melo, 2000). Além disso, a redução da relação $\mathrm{CBM} / \mathrm{Corg}$, nos três sistemas florestais (Tabela 3), também é indicação de menor eficiência relativa da microbiota, estabelecida nessas áreas, em converter os resíduos orgânicos do solo em

Tabela 3. Propriedades biológicas dos solos à profundidade de $0-10 \mathrm{~cm}^{(1)}$.

\begin{tabular}{lccccc}
\hline Espécie & CBM & $\begin{array}{c}\text { CBM/ } \\
\text { Corg }\end{array}$ & $\begin{array}{c}\text { Fosfatase } \\
\text { àcida }\end{array}$ & Arilsufatase & $\begin{array}{c}\text { Beta- } \\
\text { glicosidase }\end{array}$ \\
\hline Eucalipto & $183 \mathrm{~b}$ & $1,07 \mathrm{~b}$ & $1.118 \mathrm{~b}$ & $79 \mathrm{~b}$ & $85 \mathrm{a}$ \\
Carvoeiro & $223 \mathrm{~b}$ & $0,92 \mathrm{~b}$ & $1.452 \mathrm{a}$ & $113 \mathrm{a}$ & $71 \mathrm{ab}$ \\
Pínus & $169 \mathrm{~b}$ & $0,95 \mathrm{~b}$ & $541 \mathrm{c}$ & $33 \mathrm{c}$ & $69 \mathrm{~b}$ \\
Cerrado & $453 \mathrm{a}$ & $2,00 \mathrm{a}$ & $1.171 \mathrm{~b}$ & $83 \mathrm{~b}$ & $76 \mathrm{ab}$ \\
\hline \\
(1) Valores seguidos por letras iguais, nas colunas, não diferem entre si pelo \\
teste de Wilcoxon $(\mathrm{p}<0,10)$.
\end{tabular}

biomassa, em comparação àquela presente no solo sob cerrado. A ocorrência de efeitos antimicrobianos, relacionados às folhas de eucalipto (Mahakur \& Behera, 1999) e às acículas do pínus (Nsabimana et al., 2004), pode reduzir o crescimento microbiano, mesmo quando há recursos abundantes para isto. Em condições de estresse ambiental (nutricional, térmico, hídrico), os microrganismos derivam maior porção dos recursos energéticos disponíveis no sistema, para manter mecanismos celulares de convivência com as condições estressantes (maior custo de manutenção), em detrimento do crescimento da biomassa (Schimel et al., 2007). De fato, foram encontradas correlações positivas entre a relação $\mathrm{CBM} / \mathrm{Corg} \mathrm{e}$ as variáveis $\mathrm{pH}(\mathrm{p}<0,001 ; \mathrm{r}=0,74)$ e macroporosidade $(\mathrm{p}<0,05$; $\mathrm{r}=0,59)$, ao passo que correlação negativa foi observada entre esta relação e a saturação de alumínio (m) $(\mathrm{p}<0,001 ; \mathrm{r}=-0,79)$.

Os menores níveis de atividade enzimática (fosfatase ácida, arilsulfatase e beta-glucosidase) foram observados no solo sob pínus, embora as três áreas sob plantio de espécies florestais tenham apresentado teores semelhantes de CBM (Tabela 3). Baixos níveis de atividade enzimática, numa área sob pínus, foram observados na África do Sul (Nsabimana et al., 2004), e os autores atribuíram esse resultado aos efeitos inibitórios exercidos por compostos fenólicos presentes nas acículas. Por outro lado, o carvoeiro apresentou as maiores atividades de fosfatase ácida e arilsulfatase. Como esse plantio também apresentou um teor elevado de matéria orgânica, esse resultado indica uma maior dependência do carvoeiro da atividade dessas enzimas para a ciclagem do $\mathrm{P}$ e S orgânico. Ao se considerar que a atividade das enzimas é medida sob condições ótimas de $\mathrm{pH}$, temperatura, disponibilidade de substrato e umidade (atividade potencial), pode-se afirmar que as alterações no perfil da atividade enzimática do solo, nos plantios de pínus e carvoeiro, também refletem mudanças na estrutura funcional (taxonômica e fisiológica) da microbiota entre as áreas. Os níveis de atividade enzimática da área sob eucalipto não diferiram dos obtidos na área sob cerrado.

$\mathrm{O}$ resultado da análise de componentes principais (ACP) está apresentado na Figura 2, que representa a distribuição dos sistemas florestais, avaliados de acordo com as similaridades quanto aos atributos dos solos considerados na matriz primária. Aproximadamente $97 \%$ da variabilidade dos dados originais foram 
representadas em um gráfico de duas dimensões. Cerca de $61 \%$ dessa variabilidade foram associados ao componente principal 1 (CP1) e $36 \%$, ao componente principal 2 (CP2). Os demais $\mathrm{CP}$ não contribuíram significativamente para explicar a variação dos dados originais.

A análise conjunta dos atributos de solo discriminou os tipos de coberturas vegetais investigados (Figura 2). Essa separação foi observada principalmente ao longo do CP1, e se deu de acordo com a sequência: pínus $<$ eucalipto $<$ carvoeiro $=$ cerrado. Esse $\mathrm{CP}$ foi correlacionado a diversas variáveis de natureza física, química e biológica (Tabela 4). Essas correlações foram positivas com a atividade de fosfatase ácida e arilsulfatase, matéria orgânica, CBM, macroporosidade e porosidade total, e negativas com a densidade do solo. Com base nessas observações, é possível inferir a ocorrência de um gradiente crescente de qualidade do solo, da esquerda para a direita do CP1, em que o pínus foi a cobertura florestal que promoveu a redução mais acentuada dessa qualidade.

O CP2 foi correlacionado positivamente ao CBM e negativamente à saturação por $\mathrm{Al}(\mathrm{m} \%)$ (Tabela 4). Em razão dos seus maiores valores de CBM e menores de saturação por $\mathrm{Al}$, o cerrado nativo distinguiu-se das demais coberturas florestais ao longo desse $\mathrm{CP}$ e constituiu um agrupamento distinto (Figura 2).



Figura 2. Análise de componentes principais (ACP) com representação da distribuição das coberturas florestais, de acordo com as similaridades nas propriedades dos solos consideradas na matriz primária. A fração da variabilidade dos dados originais, representada por cada um dos componentes principais (CP), é indicada entre parênteses nos eixos da figura.
De acordo com a análise multivariada, determinada pela técnica da média recíproca, variáveis localizadas a maiores distâncias da origem da ordenação (coordenada 0) apresentam maior sensibilidade para a separação das amostras (Figura 1). Assim, observou-se que, com exceção da beta-glicosidase, os demais atributos microbiológicos (CBM, fosfatase ácida e arilsulfatase) apresentaram sensibilidade destacada em relação aos atributos físicos e químicos, para diferenciar os sistemas avaliados, o que reforça a importância da inclusão desses atributos nos estudos de impacto ambiental e de avaliação da qualidade do solo. Ao avaliar os efeitos do monocultivo de pínus, nos atributos biológicos do solo, Baretta et al. (2005) observaram que o CBM foi o atributo que mais contribuiu para aferir a dissimilaridade entre diferentes coberturas florestais. Ressalta-se que os atributos biológicos utilizados no presente estudo (biomassa microbiana e atividade enzimática) refletem vários aspectos do funcionamento do solo e foram correlacionados ao CP1 juntamente com variáveis químicas e físicas de grande importância para a qualidade do solo, como matéria orgânica, densidade, macroporosidade e porosidade total do solo (Tabela 4). Além da alta sensibilidade e da capacidade de refletir aspectos do funcionamento do solo, essas variáveis satisfazem outros critérios para bom indicador de qualidade do solo, tais como a determinação analítica simples e barata e a distribuição universal.

Por estarem em contato direto com os resíduos vegetais, as camadas mais superficiais do solo tendem a repercutir com mais intensidade os impactos das

Tabela 4. Coeficientes de correlação de Pearson, entre os atributos químicos, físicos e microbiológicos e os componentes principais 1 e 2 .

\begin{tabular}{lcc}
\hline Variáveis & \multicolumn{2}{c}{ Coeficientes de Pearson } \\
\cline { 2 - 3 } & Componente 1 & Componente 2 \\
\hline CBM & $0,664^{* *}$ & $0,824^{* *}$ \\
Fosfatase ácida & $0,903^{* *}$ & $-0,240^{\text {ns }}$ \\
Arilsulfatase & $0,875^{* *}$ & $-0,351^{\text {ns }}$ \\
Beta-glicosidase & $0,246^{\text {ns }}$ & $-0,017^{\text {ns }}$ \\
Matéria orgânica & $0,783^{* *}$ & $0,056^{\text {ns }}$ \\
CTC & $0,326^{\text {ns }}$ & $-0,316^{\text {ns }}$ \\
pH & $0,485^{\text {ns }}$ & $0,426^{\text {ns }}$ \\
Saturação por Al (m\%) & $-0,415^{\text {ns }}$ & $-0,663^{* *}$ \\
Densidade do solo & $-0,701^{* *}$ & $-0,165^{\text {ns }}$ \\
Microporosidade & $-0,237^{\text {ns }}$ & $-0,206^{\text {ns }}$ \\
Macroporosidade & $0,660^{* *}$ & $0,196^{\text {ns }}$ \\
Porosidade & $0,644^{* *}$ & $0,352^{\text {ns }}$ \\
\hline
\end{tabular}

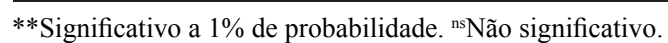


mudanças na quantidade e qualidade desses resíduos, que ocorrem em função do estabelecimento de diferentes coberturas florestais (Saggar et al., 2001). No presente trabalho, as alterações nos atributos físicos, químicos e biológicos na camada de $0-10 \mathrm{~cm}$ indicam que, passados mais de 20 anos desde o estabelecimento das coberturas florestais, um novo equilíbrio foi estabelecido no solo, e que o funcionamento do solo, nessas áreas, é diferenciado em relação ao solo sob vegetação nativa.

\section{Conclusões}

1. O reflorestamento com carvoeiro apresenta maior capacidade de preservação das propriedades físicas e do teor de matéria orgânica do solo de cerrado, em comparação ao solo com eucalipto ou pínus.

2. O teor de bases é maior, e a acidez do solo é menor em plantio de eucalipto do que em plantio de pínus ou de carvoeiro.

3. A substituição do cerrado nativo por reflorestamentos com pínus, eucalipto ou carvoeiro acarreta queda do teor de carbono da biomassa microbiana e da relação entre esta variável e o carbono orgânico.

4. A atividade potencial das enzimas do solo, fosfatase ácida e arilsulfatase, é estimulada pelo carvoeiro e inibida pelo pínus, comparativamente à cobertura de cerrado original.

5. O plantio de pínus apresenta os maiores impactos negativos sobre a qualidade geral do solo de cerrado, entre os reflorestamentos investigados.

6. Os atributos microbiológicos CBM, arilsulfatase e fosfatase ácida são mais sensíveis para diferenciar solos de cerrado, sob diferentes coberturas vegetais, do que os atributos físicos e químicos.

\section{Agradecimentos}

Ao Conselho Nacional de Desenvolvimento Científico e Tecnológico, por concessão de bolsa e apoio financeiro; ao técnico agrícola Osmar Teago de Oliveira e aos funcionários do laboratório de Microbiologia do Solo da Embrapa Cerrados, Maria das Dores Silva e Clodoaldo Alves de Sousa, pela valiosa contribuição na condução dos trabalhos.

\section{Referências}

BARETTA, D.; SANTOS, J.C.P.; FIGUEIREDO, S.R.; KLAUBERG-FILHO, O. Efeito do monocultivo de Pinus e da queima do campo nativo em atributos biológicos do solo no Planalto Sul-Catarinense. Revista Brasileira de Ciência do Solo, v.29, p.715-724, 2005.

BEHERA, N.; SAHANI, U. Soil microbial biomass and activity in response to Eucalyptus plantation and natural regeneration on tropical soil. Forest Ecology and Management, v.174, p.1-11, 2003.

BINKLEY, D.; GIARDINA, C. Nitrogen fixation in tropical forest plantations. In: NAMBIAR, E.K.S.; BROWN, A.G. (Ed.). Management of soil, nutrients and water in tropical plantation forests. Camberra: Aciar, 1997. p.297-337.

CHAER, G.M.; TÓTOLA, M.R. Impacto do manejo de resíduos orgânicos durante a reforma de plantios de eucalipto sobre indicadores de qualidade do solo. Revista Brasileira de Ciência do Solo, v.31, p.1381-1396, 2007.

CHAVES, R.Q.; CORRÊA, G.F. Macronutrientes no sistema solo-Pinus caribaea Morelet em plantios apresentando amarelecimento das acículas e morte de plantas. Revista Árvore, v.29, p.691-700, 2005.

COSTA, F.S.; ALBUQUERQUE, J.A.; BAYER, C.; FONTOURA, S.M.V.; WOBETO, C. Propriedades físicas de um Latossolo Bruno afetada pelos sistemas plantio direto e preparo convencional. Revista Brasileira de Ciência do Solo, v.27, p.527-535, 2003.

EMBRAPA. Serviço Nacional de Levantamento e Conservação de Solos. Manual de métodos de análise de solos. 2.ed. Rio de Janeiro: Embrapa, 1997. 212p.

FONSECA, S.; BARROS, N.F.; NOVAIS, R.F.; COSTA, L.M.; LEAL, P.G.L.; NEVES, J.C.L. Alterações em um Latossolo sob eucalipto, mata natural e pastagem. I. Propriedades físicas e químicas. Revista Árvore, v.17, p.271-288, 1993.

GAMA-RODRIGUES, E.F. da; BARROS, N.F. de; VIANA, A.P.; SANTOS, G. de A. Alterações na biomassa e na atividade microbiana da serapilheira e do solo, em decorrência da substituição de cobertura florestal nativa por plantações de eucalipto, em diferentes sítios da Região Sudeste do Brasil. Revista Brasileira de Ciência do Solo, v.32, p.1489-1499, 2008a.

GAMA-RODRIGUES, E.F. da; GAMA-RODRIGUES, A.C. da; PAULINO, G.M.; FRANCO, A.A. Atributos químicos e microbianos de solos sob diferentes coberturas vegetais no norte do Estado do Rio de Janeiro. Revista Brasileira de Ciência do Solo, v.32, p.1521-1530, 2008b.

GARAY, I.; KINDEL, A.; CARNEIRO, R.; FRANCO, A.A.; BARROS, E.; ABBADIE, L. Comparação da matéria orgânica e de outros atributos do solo entre plantações de Acacia mangium e Eucalyptus grandis. Revista Brasileira de Ciência do Solo, v.27, p.705-712, 2003.

GIDDENS, K.M.; PARFITT, R.L.; PERCIVAL, H.J. Comparison of some soil properties under Pinus radiata and improved pasture. New Zealand Journal of Agricultural Research, v.40, p.409-416, 1997. 
JACKSON, D.A. Stopping rules in principal component analysis: a comparison of heuristic and statistical approaches. Ecology, v.74, p.2204-2214, 1993.

JUVENAL, T.L.; MATTOS, R.L.G. O setor florestal no Brasil e a importância do reflorestamento. BNDES Setorial, n.16, p.3-30, 2002.

MAHAKUR, D.; BEHERA, N. Decomposition of Eucalyptus leaf liter in field conditions. Ecology Environment and Conservation, v.5, p.65-68, 1999.

MARCHIORI JÚNIOR, M.; MELO, W.J. de. Alterações na matéria orgânica e na biomassa microbiana em solo de mata natural e submetido a diferentes manejos. Pesquisa Agropecuária Brasileira, v.35, p1177-1182, 2000.

MCCUNE, B.; GRACE, J.B. Analysis of ecological communities. Gleneden Beach: MjM Software, 2002. 304p.

NELSON, D.W.; SOMMERS, L.E. Total carbon, organic carbon and organic matter. In: PAGE, A.L.; MILLER, R.H.; KEENEY, D.R. (Ed.). Methods of soil analysis. Madison: Soil Science Society of America, 1982. p.539-580.

NOBLE, A.D.; RANDALL, P.J. The impact of trees and fodder shrubs on soil acidification. Barton: Rural Industries Research and Development Corporation, 2005.

NSABIMANA, D.; HAYNES, R.J.; WALLIS, F.M. Size, activity and catabolic diversity of the soil microbial biomass as affected by land use. Applied Soil Ecology, v.26, p.81-92, 2004.

RHOADES, C.; BINKLEY, D. Factors influencing decline in soil pH in Hawaiian Eucalyptus and Albizia plantations. Forest Ecology and Management, v.80, p.47-56, 1996.

SAGGAR, S.; HEDLEY, C.B.; SALT, G.J. Soil microbial biomass, metabolic quotient, and carbon and nitrogen mineralisation in 25-year-old Pinus radiata agroforestry regimes. Australian Journal of Soil Research, v.39, p.491-504, 2001.

SCHIMEL, J.; BALSER, T.C.; WALLENSTEIN, M. Microbial stress-response physiology and its implications for ecosystem function. Ecology, v.88, p.1386-1394, 2007.
SCHOENHOLTZ, S.H.; MIEGROET, H. van; BURGER, J.A. A review of chemical and physical properties as indicators of forest soil quality: challenges and opportunities. Forest Ecology and Management, v.138, p.335-356, 2000.

SOCIEDADE BRASILEIRA DE SILVICULTURA. Fatos e números do Brasil florestal. São Paulo: Sociedade Brasileira de Silvicultura, 2007. 109p.

TABATABAI, A. Soil enzymes. In: WEAVER, R.W.; ANGLE, J.S.; BOTTOMLEY, P.S. (Ed.). Methods of soil analyses. Part 2. Microbiological and biochemical properties. $2^{\text {nd }}$ ed. Madison: Soil Science Society of America, 1994. p.775-833.

TER BRAAK, C.J.F.; LOOMAN, C.W.N. Weighted averaging, logistic regression and the Gaussian response model. Vegetatio, v.65, p.3-11, 1986.

VANCE, E.D.; BROOKES, P.C.; JENKINSON, D.S. An extraction method for measuring soil microbial biomass-C. Soil Biology and Biochemistry, v.19, p.703-707, 1987.

WHITTAKE, R.H. Gradient analysis of vegetation. Biological Reviews of the Cambridge Philosophical Society, v.42, p.207-264, 1967.

YAMASHITA, N.; OHTA, S.; HARDJONO, A. Soil changes induced by Acacia mangium plantation establishment: comparison with secondary forest and Imperata cylindrica grassland soils in South Sumatra, Indonesia. Forest Ecology and Management, v.254, p.362-370, 2008.

ZAIA, F.C.; GAMA-RODRIGUES, A.C. Ciclagem e balanço de nutrientes em povoamentos de eucalipto na Região NorteFluminense. Revista Brasileira de Ciência do Solo, v.28, p.843-852, 2004.

ZINN, Y.L.; RESCK, D.V.S.; SILVA, J.E. Soil organic carbon as affected by afforestation with Eucalyptus and Pinus in the Cerrado region of Brazil. Forest Ecology and Management, v.166, p.285-294, 2002.

$\overline{\text { Recebido em } 30 \text { de março de } 2009 \text { e aprovado em } 29 \text { de maio de } 2009}$ 